Archived version from NCDOCKS Institutional Repository http://libres.uncg.edu/ir/asu/

\title{
Appalachl̈ăn
}

B O O N E, N O R T H C A R O L I N A

\section{CONSUMPTION BENEFITS OF NATIONAL HOCKEY LEAGUE GAME TRIPS ESTIMATED FROM REVEALED AND STATED PREFERENCE DEMAND DATA}

Authors

JOHN C. WHITEHEAD, BRUCE K. JOHNSON, DANIEL S. MASON and GORDON J.WALKER

\begin{abstract}
This paper examines the demand for hockey game trips among metropolitan and nonmetropolitan residents of Alberta, Canada. Using data on both revealed and stated preference game-trip behavior from a telephone survey conducted throughout Alberta, we estimate the effect of ticket prices, team quality, arena amenities, and capacity on the latent demand for National Hockey League hockey games. We find that lower ticket prices, higher team quality, and additional capacity encourage attendance. In the status quo scenario, consumer surplus per game is $\$ 50$ for those who had attended hockey games and about 50\% less for those who had not attended games. Exploiting the stated preference data, we develop a number of other consumer surplus estimates. We also include travel costs in the estimation of the demand function and estimate the full value of the game trip considering both ticket prices and travel costs. Sold-out arenas in Calgary and Edmonton generate annual consumption benefits of $\$ 40$ and $\$ 35$ million when only ticket prices are used to calculate consumer surplus (i.e., excluding travel costs). Considering the full-price consumer surplus for the Calgary Flames of $\$ 103$ per game trip, the annual consumption benefits may be as high as $\$ 82$ million. (JEL R22, L83, D61)
\end{abstract}

Whitehead, John C., Bruce L. Johnson, Daniel S. Mason and Gordon J. Walker(2013) "Consumption Benefits of National Hockey League Game Trips Estimated from Revealed and Stated Preference Demand Data" Economic Inquiry 51(1):pp. 1012-1025 


\title{
CONSUMPTION BENEFITS OF NATIONAL HOCKEY LEAGUE GAME TRIPS ESTIMATED FROM REVEALED AND STATED PREFERENCE DEMAND DATA
}

\author{
JOHN C. WHITEHEAD, BRUCE K. JOHNSON, DANIELS. MASON and GORDON J. WALKER*
}

\begin{abstract}
This paper examines the demand for hockey game trips among metropolitan and nonmetropolitan residents of Alberta, Canada. Using data on both revealed and stated preference game-trip behavior from a telephone survey conducted throughout Alberta, we estimate the effect of ticket prices, team quality, arena amenities, and capacity on the latent demand for National Hockey League hockey games. We find that lower ticket prices, higher team quality, and additional capacity encourage attendance. In the status quo scenario, consumer surplus per game is $\$ 50$ for those who had attended hockey games and about 50\% less for those who had not attended games. Exploiting the stated preference data, we develop a number of other consumer surplus estimates. We also include travel costs in the estimation of the demand function and estimate the full value of the game trip considering both ticket prices and travel costs. Soldout arenas in Calgary and Edmonton generate annual consumption benefits of $\$ 40$ and $\$ 35$ million when only ticket prices are used to calculate consumer surplus (i.e., excluding travel costs). Considering the full-price consumer surplus for the Calgary Flames of $\$ 103$ per game trip, the annual consumption benefits may be as high as $\$ 82$ million. (JEL R22, L83, D61)
\end{abstract}

\section{INTRODUCTION}

When the Baltimore Orioles moved from their 1950s-vintage home in Memorial Stadium to Oriole Park at Camden Yards in 1992, a new era in stadium and arena construction dawned in North American professional sports. The greatly

\footnotetext{
* Preparation of this manuscript was supported by a grant from the Alberta Gaming Research Institute. The authors would like to thank the University of Alberta Population Research Lab staff for their assistance collecting the data and Glenn Blomquist, Jeff Borland, Philip Porter, Stefan Szymanski, and two anonymous referees for a number of comments and suggestions that have greatly improved this paper. Previous versions of this paper were presented in seminars at the University of Kentucky and Appalachian State University and in a session at the 2008 Southern Economic Association meetings.

Whitehead: Department of Economics, Appalachian State University, Boone, NC 28607. Phone 828-262-6121, Fax 828-262-6105, E-mail whiteheadjc@appstate.edu

Johnson: Department of Economics, Centre College, Danville, KY 40422. Phone 859-238-5255, Fax 859-2389610, E-mail bruce.johnson@ @entre.edu

Mason: Faculty of Physical Education \& Recreation, University of Alberta, Edmonton, AB, T6G 2H9, Canada. Phone 780-492-6822, Fax 780-492-1008, E-mail dmason@ualberta.ca

Walker: Faculty of Physical Education \& Recreation, University of Alberta, Edmonton, AB, T6G 2H9, Canada. Phone 780-492-0581, Fax 780-492-2364, E-mail gordon.walker@ualberta.ca
}

enhanced premium seating, luxury suites, concessions, sight lines, and other amenities made possible by advances in architectural design and construction technology led to large increases in revenues for the Orioles. Teams in Major League Baseball (MLB), the National Football League (NFL), the National Basketball Association (NBA), and the National Hockey League (NHL) joined the rush to replace their now economically obsolete arenas and stadiums with their own versions of Camden Yards. Of the 30 NHL teams, 25 have moved into new arenas since 1993. Several other facilities are under consideration.

Two teams that have not moved into new arenas are the Edmonton Oilers and the Calgary Flames, Alberta's two teams in the NHL. The Oilers continue to play in Rexall Place, located

\section{ABBREVIATIONS}

CBM: Contingent Behavior Method CVM: Contingent Valuation Method MLB: Major League Baseball NBA: National Basketball Association NFL: National Football League

NHL: National Hockey League 
just outside downtown Edmonton, which opened in 1974. The Flames play in the Scotiabank Saddledome, dating from 1983. Management of both teams complain of a lack of space for luxury suites and other premium seating, as well as cramped facilities for concessions, placing them at a competitive disadvantage with other teams in the league (Kom 2008; Mah 2007).

As a result, a need for new facilities has been expressed in both cities, where discussion has focused on where the new arenas would be sited and to what extent they would be publicly financed (Mason 2010). This paper takes the opportunity presented by the possibility of new NHL arenas in Alberta to examine the demand for hockey game trips among residents of Edmonton, Calgary, and the rest of the province of Alberta. Using data on both revealed and stated preferences from a telephone survey conducted throughout Alberta, we estimate the effect of ticket prices, team quality, arena amenities, and capacity on the latent demand for NHL hockey. Unlike most attendance studies, we measure private consumption benefits of new arenas, in the form of consumer surplus, to current and future game attendees. Furthermore, unlike the one previous study that econometrically estimated consumer surplus for game attendance (Irani 1997), this paper includes data on travel costs in the estimation of the demand function, allowing an estimate of the full consumer surplus.

\section{LITERATUREREVIEW}

Economists have conducted many empirical analyses of the demand for attendance at sporting contests. Borland and Macdonald (2003) discuss the conceptual issues and provide a theoretical discussion of the demand for sporting events. Two studies in particular are relevant to this paper because they address the impact of new stadiums and arenas on season attendance. Zygmont and Leadley (2005) use a panel data set of season attendance spanning 1970-2000 in MLB to estimate the "honeymoon effects" of a new stadium on attendance and ticket prices, and find substantial positive effects on both that persist, with only modest declines, for 8-10 years. They conclude that a baseball-only stadium that replaces an older multipurpose stadium will generate an additional \$228 million in ticket revenue over 15 years.

Leadley and Zygmont (2006) test for honeymoon effects in the NHL from 1970 to 2003 using Tobit analysis as the capacity constraint is usually binding in the NHL, unlike in MLB. For instance, during the 2009-2010 season, 11 NHL teams achieved season attendance greater than or equal to $100 \%$ of seating capacity with an additional 6 teams operating at better than $97 \%$ capacity. In MLB in 2010, five total teams exceeded $90 \%$, with only three of those playing to full capacity for the entire season. The honeymoon effect in the NHL from 1994 to 2003, a period in which 21 new arenas opened, increased an NHL team's attendance by $15 \%-20 \%$ and the honeymoon lasted eight years.

There have been many other attendance studies, most of them focusing on game-by-game attendance rather than season attendance. Baseball and soccer attendance have been studied more often than attendance in other sports (Borland and Macdonald 2003). Among the many baseball articles are Bruggink and Eaton (1996), Kahane and Shmanske (1997), Butler (2002), Coates and Harrison (2005), and Donihue, Findlay, and Newberry (2007). Soccer attendance in European leagues has been the subject of studies by Garcia and Rodriguez (2002) and Czarnitzki and Stadtmann (2002), among others. Welki and Zlatopper (1994, 1999) estimated game-day attendance in the NFL, while Price and Sen (2003) did so for Division I-A (now called the Football Bowl Subdivision) college football. Attendance at NBA games has been estimated by Burdekin and Idson (1991), and attendance at NHL games by Paul (2003).

Despite the differences in locations, time periods, and sports, the attendance studies have found broadly similar results. Most studies have found that ticket prices have a negative impact on attendance, though not always, and that except for Bruggink and Eaton (1996), demand tends to be inelastic with respect to price. The inelasticity of demand is surprising considering that the local monopolies usually enjoyed by professional sports teams should result in prices where demand is price-elastic. Many studies have also found that income affects demand, with sports more often than not being a normal good. However, in some cases, as in baseball (Bruggink and Eaton 1996), a sport appears to be an inferior good, even as the same sport appears to be a normal good in other studies. Quality of competition consistently proves significant: the better the home team and its opponent, the higher the attendance.

Irani (1997) estimates a demand function for MLB using actual 1985 season attendance, 
as opposed to the usual game-by-game attendance, and ticket price data. Using his estimates to calculate the choke price for MLB tickets and integrating the estimated attendance function over the range of ticket prices, he calculates average annual consumer surplus of about \$35 million (2007 dollars) per team (Irani 1997). Alexander, Kern, and Neill (2000) calculate consumer surplus by assuming a constant elasticity demand function, and combine evidence of team revenues with assumptions about different demand elasticities. Not surprisingly, the amount of consumer surplus depends strongly on the value of the assumed elasticity. Alexander, Kern, and Neill did not estimate any demand functions or price elasticities with attendance data.

Methods developed by environmental economists to measure the value of public and private benefits of consumption provide the means to improve upon the estimates of sports consumer surplus developed by Irani and Alexander, Kern, and Neill. In this paper, we use the travel cost method, which is a revealed preference method most often used to estimate recreation benefits (Phaneuf and Smith 2005), but it has also been used to estimate the benefits of other goods such as health care (Clarke 2002). The travel and time costs incurred to get to an activity site can constitute a major cost of participating in the recreation activity. As individuals reside at varying distances from stadiums, the variation in distance and the number of trips taken can be used to estimate a demand function and derive the benefits of attendance and stadium characteristics. Revealed preference approaches are limited to the variation in historical experience. Forecasts beyond are often inaccurate or impossible.

Stated preference methods provide additional tools to estimate the benefits of sporting events and amenities. Stated preference approaches include the contingent valuation method (CVM) and the contingent behavior method (CBM). The CVM uses willingness to pay responses to hypothetical situations to estimate benefits. Over the past decade or so, economists have extended the use of CVM to sports in order to estimate the use and nonuse values of sports public goods. In the seminal CVM sports article, Johnson and Whitehead (2000) survey respondents in Lexington, Kentucky, who are asked whether and how much they would be willing to pay for a new basketball arena for the University of Kentucky and for a baseball stadium to attract a minor league team. For both projects, the nonmarket benefits fall short of the costs of constructing the new buildings.

Since Johnson and Whitehead (2000) there have been a number of CVM studies of sports public goods. Civic unity, community pride, improved racial relations, and topics of conversation are some of the public goods addressed by sports CVM studies covering the NFL, NBA, MLB, amateur participatory sports, and the Olympics (Johnson 2008). Although the later CVM studies tend to find substantially larger values of sports public goods than did Johnson and Whitehead, peer-reviewed sports CVM articles tend to find that the value of sports public goods fall short of the cost of constructing arenas, stadiums, and other venues, except in the case of the Minnesota Vikings of the NFL (Fenn and Crooker 2009). ${ }^{1}$

In contrast to the CVM, the CBM is a stated preference approach that directly elicits hypothetical behavior information from survey respondents. Respondents are asked about their behavioral responses to a hypothetical change. One strength of the CBM approach is its flexibility. Hypothetical choices may be the only way to gain policy-relevant behavior information about situations where revealed preference data are not available. Yet, the major weakness of the CBM approach is its hypothetical nature. Respondents face unfamiliar situations with incomplete information. To date, the CBM has not been applied to sports attendance behavior.

The combination and joint estimation of revealed and stated preference data exploit the contrasting strengths of the alternative approaches while minimizing their weaknesses (Whitehead et al. 2008). Stated preference data allow analysis of behavior beyond the range of historical experience. In many cases, hypothetical choices may not reflect budget, and other, constraints on behavior. For example, in a contingent behavior survey, respondents may answer a hypothetical game trip question with their good intentions of buying season tickets and going to every game. Yet, when they must make real choices, they confront unexpected constraints on time and income and make fewer game trips. Combining revealed preference and stated preference data allows mitigation of the

1. Other methods that have been or could be used to value sports amenities include the hedonic price method (Carlino and Coulson 2004, 2006; Coates, Humphreys, and Zimbalist 2006), public referenda (Coates and Humphreys 2006), or a combination of the two (Dehring, Depken, and Ward 2008). 
bias associated with hypothetical choices present in stated preference data. Grijalva et al. (2002) and Whitehead (2005) find evidence that jointly estimated revealed and stated preference models generate valid predictions of future behavior.

In contrast to previous research valuing sports-related goods and services that rely solely on revealed preference data or the CVM, we jointly estimate a demand model using revealed and stated preference data. In the rest of the paper we summarize the survey data, describe the empirical methods, and present the empirical results. Conclusions follow.

\section{SURVEY DATA}

A telephone survey conducted during late 2007 and early 2008 collected revealed preference and stated preference data. A random sample frame of telephone numbers for the Edmonton and Calgary metropolitan areas and for the rest of Alberta was generated. The initial screening questions selected either a male or female potential respondent aged 18 years or older. Based on pre-established quotas, data were collected from 937 people (Edmonton, $n=339$; Calgary, $n=331$; nonmetropolitan Alberta, $n=267$ ). In order to meet the quota requirements, 6,764 telephone numbers were called, with 1,610 of these numbers being excluded for technical reasons (e.g., not in service, busy/no answer), and another 2,346 numbers being excluded for noneligibility and other reasons (e.g., business fax, less than 18 years of age, unable to speak English). Another 1,871 people refused to participate, resulting in an overall response rate of 33\% (i.e., 937/[937+ $1,871])$.

The study instrument consisted of a computer-assisted telephone interviewing questionnaire that included a description of a new downtown hockey arena with various features ${ }^{2}$ :

Suppose the Flames/Oilers decide to build a new, state-of-the-art hockey arena [in a complex that would also include affordable housing, arts and cultural space including galleries, theaters and museum space, and a casino] in downtown Calgary/Edmonton to replace the Pengrowth Saddledome/Rexall Place. [Suppose environmentally friendly materials and design will be used.] Some people say that building the arena, [housing, cultural complex, and casino] downtown would improve the quality of life in Calgary/Edmonton more than building it in the suburbs.

2. Pengrowth Saddledome was renamed Scotiabank Saddledome in 2010.
Respondents in the Edmonton and Calgary surveys received various combinations of arena characteristics ranging from a new arena with no additional characteristics and an arena with four additional characteristics (green design, affordable housing, cultural complex, and a casino).

The revealed preference data are based on hockey game trips that actually occurred during the 2006-2007 season. The stated preference data are based on future hockey game trips under various hypothetical conditions. The stated preference data are used to simulate a change in demand resulting from changes in the quality of the hockey game experience, increased seating availability, and changes in ticket prices (see Appendix). Stated preference questions asked about future trips to the current arena: (1) with an expected first place finish, (2) with an expected last place finish, and (3) with an expected third place finish. Questions were then asked about future trips to a new downtown arena with additional upper level seating and a third place finish: (1) with a $\$ 15$ ticket price decrease from the lowest walk-up ticket price, (2) with a $\$ 25$ ticket price decrease from the lowest walk-up ticket price, and (3) with a $\$ 5$ ticket price decrease from the lowest walk-up ticket price. The combined revealed and stated preference pseudo-panel data have seven observations for each respondent.

Respondents in the Edmonton and Calgary surveys were asked questions about Oilers and Flames games, respectively. Respondents in the nonmetropolitan Alberta survey were asked "About how often do you visit Calgary/ Edmonton?" Respondents who visit Calgary more often are considered in the Flames market and asked questions about trips to Flames games. Respondents who visit Edmonton more often are considered in the Oilers market and asked questions about trips to Oilers games. Respondents were also asked "How long does it usually take you to get to Calgary/Edmonton?" The average number of hours traveled is 4 to Calgary and 3 to Edmonton. Seventy-two percent of nonmetropolitan Alberta respondents visit the city with the lowest travel time more often. Hours traveled is converted to distance traveled assuming an average speed of $75 \mathrm{~km} / \mathrm{hr}$.

Of the 937 completed interviews, we discard those cases with no response to the stated preference attendance and other key questions. We employ a sample of 828 respondents. Table 1 presents a summary of the game-trip-dependent variable. We present the data in terms of four 
TABLE 1

Dependent Variables-Games Attended in Various Scenarios

\begin{tabular}{|c|c|c|c|c|c|c|c|c|c|c|}
\hline & \multirow[b]{2}{*}{ Scenario } & & \multicolumn{4}{|c|}{ Calgary Flames } & \multicolumn{4}{|c|}{ Edmonton Oilers } \\
\hline & & & \multicolumn{2}{|c|}{ Attend = 1} & \multicolumn{2}{|c|}{ Attend $=0$} & \multicolumn{2}{|c|}{ Attend $=1$} & \multicolumn{2}{|c|}{ Attend $=0$} \\
\hline Arena & $\begin{array}{l}\text { Price (Flames, } \\
\text { Oilers) }\end{array}$ & Finish & Mean & $\begin{array}{l}\text { Standard } \\
\text { Deviation }\end{array}$ & Mean & $\begin{array}{l}\text { Standard } \\
\text { Deviation }\end{array}$ & Mean & $\begin{array}{l}\text { Standard } \\
\text { Deviation }\end{array}$ & Mean & $\begin{array}{l}\text { Standard } \\
\text { Deviation }\end{array}$ \\
\hline Old & $\mathrm{RP}^{\mathrm{a}}$ & 3,5 & 5.19 & 7.85 & 0.00 & 0.00 & 3.84 & 4.42 & 0.00 & 0.00 \\
\hline Old & 35,45 & 1 & 7.08 & 11.86 & 0.27 & 0.80 & 5.76 & 9.10 & 0.57 & 2.85 \\
\hline Old & 35,45 & 5 & 5.62 & 10.53 & 0.13 & 0.66 & 4.87 & 10.42 & 0.23 & 0.91 \\
\hline Old & 35,45 & 3 & 5.95 & 10.31 & 0.19 & 0.70 & 4.97 & 7.86 & 0.32 & 0.97 \\
\hline New & 20,30 & 3 & 10.47 & 13.52 & 1.67 & 5.20 & 7.85 & 12.77 & 1.44 & 4.12 \\
\hline New & 10,20 & 3 & 13.30 & 15.59 & 2.68 & 7.34 & 9.48 & 13.54 & 2.10 & 5.57 \\
\hline New & 30,40 & 3 & 8.99 & 12.19 & 1.13 & 3.62 & 6.35 & 8.28 & 0.81 & 1.65 \\
\hline Cases & & & \multicolumn{2}{|r|}{133} & \multicolumn{2}{|r|}{246} & \multicolumn{2}{|r|}{148} & \multicolumn{2}{|r|}{301} \\
\hline
\end{tabular}

Notes: The mean figures show the average number of games attended in various scenarios. Those in Row 1 are the average games actually attended, according to revealed preference responses. Those in Rows $2-7$ are stated preference averages under scenarios that differ according to whether the arena is old or new, ticket prices, and divisional finish. The responses in each of the two markets are broken down among those who attended games in 2006-2007 (Attend =1) and those who did not (Attend $=0$ ).

${ }^{a}$ Revealed preference during 2006-2007 season.

subsamples: (1) Flames market respondents who attended a game during the 2006-2007 season ( $n=133)$; (2) Flames market respondents who had not attended a game $(n=246)$; (3) Oilers market respondents who had attended a game ( $n=148)$; and (4) Oilers market respondents who had not attended a game $(n=301)$. Those in the Flames market who had attended at least one game attended an average of five games during the past season (5.19 in Table 1; we report rounded values in the text). Those in the Oilers market who had attended at least one game attended an average of four games during the past season. ${ }^{3,4}$

In each subsample a similar pattern appears in each hypothetical scenario. Under the current arena and price scenario, respondents state they would attend about the same number of games regardless of the team's expected finish. With a new arena and lower ticket prices, respondents who had attended a game during the past season said that their future attendance would roughly double. With a new arena and lower ticket prices, respondents who had not attended a game during the past season said that their future attendance would also increase significantly.

3. These data exhibit digit bias which is one strategy that respondents rely on when recall is difficult (Tarrant and Manfredo 1993). Measurement error in the dependent variable should not bias regression coefficient efficient estimates but it could lead to inflated standard errors.

4. NHL teams host 41 regular season games each season.
Table 2 presents descriptive statistics for the independent variables. ${ }^{5}$ The self-reported ticket price paid by Flames and Oilers game attendees is $\$ 82$ and $\$ 78$, respectively. ${ }^{6}$ Several differences across subsamples emerge. The average travel cost is lower for attendees relative to nonattendees, suggesting that travel distance is a factor in the game trip decision. ${ }^{7}$ The average household income is higher for attendees compared to nonattendees, suggesting that respondent ability to pay may be a factor in the game trip decision. ${ }^{8}$ In both markets male respondents are more likely to attend games. Game attendees are younger relative to nonattendees. Perhaps because Scotiabank Saddledome is closer to Calgary's downtown than Rexall Place is to

5. Our sample is slightly older and more affluent than the population.

6. Ticket prices paid for Flames and Oilers games range from $\$ 11$ to $\$ 300$ and $\$ 20$ to $\$ 179$, suggesting that the reported price paid includes secondary market purchases.

7. Travel cost is computed as $c=\alpha d+$ $(\theta y / h)(d / m p h)$, where $\alpha$ is the average cost per mile (including gas, oil, and depreciation), $d$ is round-trip distance, $\theta$ is the opportunity cost of time, $0<\theta<1, y$ is household income, $h$ is annual work hours, and mph is average miles per hour. We use the following values: $\alpha=0.32, \theta=0.33, h=2000$, and $m p h=75 \mathrm{k} / \mathrm{h}$. These values are not unusual in the literature (Phaneuf and Smith 2005); however, our results are likely sensitive to alternative values (Hynes, Hanley, and O'Donoghue 2009).

8. Sixteen percent of the income variables are imputed using an income regression $\left(R^{2}=0.27\right)$. In this model income increases with education and age (at a diminishing rate). Income is higher for males, married respondents, and metro respondents (relative to rural Albertans). 
TABLE 2

Independent Variables

\begin{tabular}{|c|c|c|c|c|c|c|c|c|c|}
\hline \multirow[b]{3}{*}{ Variable } & \multirow[b]{3}{*}{ Description } & \multicolumn{4}{|c|}{ Calgary Flames } & \multicolumn{4}{|c|}{ Edmonton Oilers } \\
\hline & & \multicolumn{2}{|c|}{ Attend $=1$} & \multicolumn{2}{|c|}{ Attend $=0$} & \multicolumn{2}{|c|}{ Attend = 1} & \multicolumn{2}{|c|}{ Attend $=0$} \\
\hline & & Mean & $\begin{array}{l}\text { Standard } \\
\text { Deviation }\end{array}$ & Mean & $\begin{array}{l}\text { Standard } \\
\text { Deviation }\end{array}$ & Mean & $\begin{array}{l}\text { Standard } \\
\text { Deviation }\end{array}$ & Mean & $\begin{array}{l}\text { Standard } \\
\text { Deviation }\end{array}$ \\
\hline RP-PRICE & Actual ticket price & 82.08 & 35.87 & - & - & 78.33 & 23.50 & - & - \\
\hline TRAVCOST & $\begin{array}{l}\text { Travel cost to } \\
\text { downtown }\end{array}$ & 26.36 & 67.45 & 43.75 & 65.76 & 39.47 & 57.68 & 59.87 & 83.35 \\
\hline INCOME & $\begin{array}{l}\text { Household income } \\
\qquad(\$ 1,000 \mathrm{~s})\end{array}$ & 110.86 & 35.23 & 77.30 & 36.99 & 93.78 & 38.09 & 70.57 & 39.30 \\
\hline MALE & 1 if male & 0.63 & 0.48 & 0.43 & 0.50 & 0.59 & 0.49 & 0.39 & 0.49 \\
\hline MARRIED & 1 if married & 0.73 & 0.45 & 0.65 & 0.48 & 0.72 & 0.45 & 0.71 & 0.45 \\
\hline AGE & Age of respondent & 42.83 & 13.66 & 50.15 & 15.25 & 43.28 & 14.49 & 51.68 & 16.46 \\
\hline EDUC & Years of schooling & 14.50 & 2.10 & 14.11 & 2.22 & 13.84 & 2.12 & 13.73 & 2.59 \\
\hline LIVE & $\begin{array}{l}1 \text { if lives in } \\
\text { downtown }\end{array}$ & 0.08 & 0.26 & 0.06 & 0.24 & 0.02 & 0.14 & 0.05 & 0.22 \\
\hline WORK & $\begin{array}{l}1 \text { if works in } \\
\text { downtown }\end{array}$ & 0.25 & 0.43 & 0.11 & 0.31 & 0.13 & 0.34 & 0.11 & 0.31 \\
\hline PROPERTY & $\begin{array}{l}1 \text { if owns property in } \\
\text { the area }\end{array}$ & 0.69 & 0.46 & 0.50 & 0.50 & 0.56 & 0.50 & 0.48 & 0.50 \\
\hline TENURE & $\begin{array}{l}\text { Length of time at } \\
\text { residence }\end{array}$ & 19.95 & 16.09 & 17.18 & 17.40 & 20.31 & 17.91 & 21.24 & 21.57 \\
\hline ALBERTA & 1 if Alberta survey & 0.14 & 0.34 & 0.30 & 0.46 & 0.25 & 0.43 & 0.35 & 0.48 \\
\hline Cases & & \multicolumn{2}{|c|}{133} & \multicolumn{2}{|c|}{246} & \multicolumn{2}{|r|}{148} & \multicolumn{2}{|c|}{301} \\
\hline
\end{tabular}

Edmonton's downtown, a higher proportion of Flames attendees live and work downtown. A greater number of nonattendees are from the nonmetropolitan, rest of Alberta sample. This is further evidence that travel costs may affect attendance decisions. Other variables show little difference across subsamples.

\section{EMPIRICAL MODEL}

The Poisson regression model is often used to study count data such as number of recreation trips (Haab and McConnell 2002). Assume that $x_{i t}$ is the number of revealed and stated preference hockey game trips taken by individual $i$ in scenario $t$, which is drawn from a Poisson distribution with mean $\lambda_{i t}$ :

(1) $\quad \operatorname{Pr}\left(x_{i t}\right)=\frac{\mathrm{e}^{-\lambda_{i t}} \lambda_{i t}^{x_{i t}}}{x_{i t} !}, x_{i t}=0,1,2, \ldots$

The natural $\log$ of the mean number of revealed and stated preference game trips is assumed to be a linear function of prices, income, and scenario dummy variables. To allow for variation across hockey fans that cannot be explained by the independent variables, we assume that the mean number of revealed and stated preference game trips also depends on individual specific and random error. The random effects Poisson demand model is as follows:

(2)

$$
\begin{aligned}
\ln \lambda_{i t}= & \beta_{0}+\beta_{p^{\mathrm{R}}} p_{i t}^{\mathrm{R}}+\beta_{p} p_{i y}^{\mathrm{S}}+\beta_{c} c_{i}+\beta_{y} y_{i} \\
& +\beta_{\mathrm{RPRP}}+\delta^{1} Z+\mathrm{\gamma}^{1} D+\mu_{i}+e_{i t},
\end{aligned}
$$

where $p^{\mathrm{R}}$ is the revealed preference ticket price $\left(p^{\mathrm{R}}=0\right.$ if $\left.x=0\right), p^{\mathrm{S}}$ is the stated preference ticket price, $c$ is the round-trip travel cost to the hockey arena, $y$ is income, RP is a revealed preference dummy variable; $\beta, \delta$, and $Y$ are coefficients (vectors) to be estimated; $\mu_{i}$ is the random effect for group (person) $i$ and $e_{i t}$ is a mean zero error term. Individuals are indexed $i=1, \ldots, n$, and $t=1, \ldots, 7$ denotes seasonal hockey game trip demand in the pseudo-panel data. $\boldsymbol{Z}$ is a vector of scenario design variables (i.e., new arena, new arena characteristics, and team finish) and $\boldsymbol{D}$ is a vector of demographic characteristics. The $R P$ dummy variable is included to test for bias in hypothetical responses: $\mathrm{RP}=1$ for revealed preference trip data $(t=1)$ and 0 for stated preference trip data $(t>1)$. Pooling the data suggests that panel data methods be used to account for differences in variance across sample individuals, $i$, and scenarios, $t$. The distribution 
of trips is Poisson with conditional mean and variance, $\lambda_{i t}$. If $\exp \left(\lambda_{i t}\right)$ is assumed to follow a gamma distribution, then the unconditional trips, $x_{i t}$, follow a negative binomial distribution (Hausman, Hall, and Griliches 1984).

With the semi-log functional form price, travel cost and income elasticities are $e_{p}=$ $\beta_{p} \bar{p}^{\mathrm{S}}, e_{c}=\beta_{c} \bar{c}, e_{y}=\beta_{y} \bar{y}$ when evaluated at the means of the variables. The full-price elasticity is the weighted average of the price and travel cost elasticities:

$$
e_{p c}=e_{p} \theta_{p}+e_{c} \theta_{c}
$$

where $\theta_{k}=\frac{k}{n+c}, k=p, c, \quad$ is the ticket price and travel cost share of the pull price

With the semi-log functional form the economic benefit per hockey game for the representative hockey fan as measured by average consumer surplus (CS) per game in the ticket market is (Bockstael and Strand 1987):

(4)

$$
\frac{\mathrm{CS}_{p}}{x}=-\frac{1}{\beta_{p}}
$$

The economic benefit per hockey game trip is a weighted average of the ticket price and travel cost consumer surnlus

(5)

$$
\frac{\mathrm{CS}_{p c}}{x}=-\left(\frac{1}{\beta_{p}} \theta_{p}+\frac{1}{\beta_{c}} \theta_{c}\right)
$$

The economic benetit of a change in the hockey experience per game measured by the $j$ th scenario design variable $\Delta Z_{j}$ and evaluated in the ticket market is:

$$
\frac{\Delta \operatorname{CS}_{p}(\Delta Z)}{x}=-\frac{\delta_{Z} \Delta Z}{\beta_{p}},
$$

where $\delta_{Z_{j}}$ is the regression coefficient on the $j$ th scenario design variable. The economic benefit of a change in the hockey experience per hockey

9. The panel data random effects Poisson model relaxes the equal mean and variance assumption of a cross-sectional Poisson model. It is distributed negative binomial with overdispersion parameter $\alpha$. It is the standard when estimating demand models with revealed and stated preference data combined in a pseudo-panel (Whitehead et al. 2008). The main advantage of the random effects Poisson over the random effects negative binomial is that it allows for crossequation correlation (Landry and Liu, 2011). As there are a large number of zeros in the dependent variable, zeroinflated Poisson models were also attempted in the context of random parameter and latent class Poisson models. Each of these models fits the data well. However, results lead to larger consumer surplus estimates than we present here. As, to our knowledge, no study in the revealed and stated preference literature has investigated these alternative models and that investigation is beyond the scope of this paper we leave this exploration to future research. game trip is a weighted average of the change in ticket price and travel cost consumer surplus

(7)

$$
\frac{\Delta \mathrm{CS}_{p c}(\Delta Z)}{x}=-\left(\frac{\delta_{Z} \Delta Z}{\beta_{p}} \theta_{p}+\frac{\delta_{Z} \Delta Z}{\beta_{c}} \theta_{c}\right)
$$

Equations (5) and (7) diverge from Equations (4) and (6) with statistically significant coefficients on the travel cost coefficients. If the travel cost coefficient is statistically insignificant then that term drops out of the consumer surplus equation.

\section{EMPIRICAL RESULTS}

Table 3 presents the random effects Poisson coefficient estimates for the Calgary Flames and Edmonton Oilers markets. The models include the revealed preference ticket price as an independent variable. Each model contains a dummy variable for the new arena scenario and the new arena dummy interacted with the nonmetropolitan sample (this is the only variable that indicates different behaviors across metropolitan and nonmetropolitan samples). Team finish and dummy variables for arena features, green design and construction, affordable housing, a

casino and a cultural complex are included. Each of the arena features dummy variables is coded as zero for the nonmetropolitan sample because those respondents were not asked the arena scenario questions. In addition, dummy variables for the revealed preference scenario, gender, and marital status are included. Other variables included in the model are continuous: household income, age, and years of schooling. Other variables in Table 1 are omitted from the demand models because of multicollinearity or statistical irrelevance.

We split each market into those who had revealed a preference for hockey games during the 2006-2007 season (attendees) and those who had not (nonattendees). The random effects Poisson coefficient estimates for each market and attendees and nonattendees subsamples are presented in Table 3 . In each of the attendee models, the revealed preference coefficient is negative and significant. There are two interpretations of this result. First, it might indicate hypothetical bias. In the hypothetical scenarios, respondents said that they would like to attend more games than they are actually able to attend. The second interpretation is that this result measures latent demand at the current seating capacity and ticket prices. Respondents would like to 
TABLE 3

Random Effects Panel Data Poisson Model: Hockey Game Attendance Demand (Attendee vs. Nonattendee)

\begin{tabular}{|c|c|c|c|c|c|c|c|c|}
\hline & \multicolumn{4}{|c|}{ Calgary Flames } & \multicolumn{4}{|c|}{ Edmonton Oilers } \\
\hline & \multicolumn{2}{|c|}{ Attend $=1$} & \multicolumn{2}{|c|}{ Attend $=0$} & \multicolumn{2}{|c|}{ Attend = 1} & \multicolumn{2}{|c|}{ Attend $=0$} \\
\hline & Coefficient & $t$-ratio & Coefficient & $t$-ratio & Coefficient & $t$-ratio & Coefficient & $t$-ratio \\
\hline Constant & 4.153 & 4.38 & 0.990 & 0.46 & 3.335 & 3.69 & 3.363 & 1.79 \\
\hline $\mathrm{RP}$ & -0.177 & -6.06 & & & -0.214 & -5.47 & & \\
\hline RP-PRICE & 0.002 & 0.66 & & & 0.005 & 1.03 & & \\
\hline SP-PRICE & -0.020 & -15.66 & -0.044 & -23.12 & -0.020 & -10.63 & -0.046 & -14.60 \\
\hline TRAVCOST & -0.004 & -2.52 & -0.001 & -0.20 & -0.001 & -0.61 & 0.002 & 0.51 \\
\hline NEWARENA & 0.237 & 9.80 & 1.943 & 28.86 & 0.004 & 0.13 & 0.718 & 9.41 \\
\hline NEWARENA $\times$ ALBERTA & 0.341 & 11.35 & -0.387 & -3.16 & 0.420 & 19.14 & 0.663 & 7.68 \\
\hline FINISH & -0.058 & -7.81 & -0.241 & -2.95 & -0.043 & -4.90 & -0.386 & -11.90 \\
\hline INCOME & 0.001 & 0.26 & 0.006 & 0.89 & 0.007 & 2.26 & -0.003 & -0.62 \\
\hline MALE & 0.051 & 0.26 & 0.069 & 0.14 & 0.334 & 1.63 & 0.404 & 1.09 \\
\hline MARRIED & 0.230 & 0.82 & 0.415 & 0.73 & -0.421 & -1.86 & -0.031 & -0.06 \\
\hline AGE & -0.019 & -2.32 & -0.034 & -2.26 & -0.014 & -1.81 & -0.047 & -3.23 \\
\hline EDUC & -0.083 & -1.24 & -0.001 & -0.01 & -0.079 & -1.74 & 0.003 & 0.03 \\
\hline GREEN & 0.271 & 1.16 & 0.261 & 0.37 & -0.045 & -0.17 & -0.335 & -0.71 \\
\hline CASINO & 0.225 & 0.75 & -0.082 & -0.10 & -0.024 & -0.08 & 1.362 & 2.00 \\
\hline HOUSING & 0.285 & 0.86 & 0.243 & 0.33 & -0.172 & -0.61 & -0.075 & -0.13 \\
\hline ARTS & -0.616 & -1.90 & -0.607 & -0.74 & 0.347 & 1.17 & 0.876 & 1.29 \\
\hline$\alpha$ & 1.185 & 5.93 & 5.591 & 7.57 & 0.914 & 7.89 & 4.731 & 7.88 \\
\hline LL & \multicolumn{2}{|c|}{-2733} & \multicolumn{2}{|c|}{-1198} & \multicolumn{2}{|c|}{-2703} & \multicolumn{2}{|c|}{-1508} \\
\hline Cases & \multicolumn{2}{|c|}{133} & \multicolumn{2}{|c|}{246} & \multicolumn{2}{|c|}{148} & \multicolumn{2}{|c|}{301} \\
\hline Periods & \multicolumn{2}{|c|}{7} & \multicolumn{2}{|c|}{7} & \multicolumn{2}{|c|}{7} & \multicolumn{2}{|c|}{7} \\
\hline
\end{tabular}

attend more games but game sell-outs constrain their behavior.

\section{A. Prices and Income}

The effect of revealed preference ticket price on the number of games attended is ambiguous because current game trips are quantity constrained, ticket price reflects quality, and ticket price is partially endogenous as an increasing function of income in the secondary market. In each model, the actual ticket price coefficient is not significantly different from zero. The coefficient on the stated preference price variable is negative and statistically significant, as expected. Demand is inelastic across markets: $e_{p}=-0.57$ for Calgary and $e_{p}=-0.77$ for Edmonton. ${ }^{10}$ The coefficient on the travel cost

10. Economic theory indicates that each dollar of cost should be considered equivalently by consumers, suggesting that ticket price and travel cost should be added together to form a single cost variable. However, model performance is superior with these variables entered separately. This suggests that consumers respond differently to the two types of cost. Perhaps, the travel cost variable is capturing the cost of multipurpose trips. In addition to a hockey game, respondents could also enjoy shopping or dining in the area. variable is negative and statistically significant in the Calgary attendee model. The travel cost elasticity is $e_{c}=-0.10$ for Calgary and the fullprice elasticity is $e_{p c}=-0.45$ in the Calgary attendee model. ${ }^{11}$ The coefficient on the income variable is positive and statistically significant in the Edmonton attendee model. The income elasticity is $e_{y}=0.78$. Other price and income coefficients are not statistically significant. In each nonattendee model, the coefficient on the stated preference price variable is negative and statistically significant. Demand is elastic: $e_{p}=-1.25$ for Calgary and $e_{p}=-1.78$ for Edmonton. The coefficients on the travel cost and income variables are statistically insignificant in each nonattendee model.

\section{B. Capacity}

In each model, a new downtown arena with plenty of upper level seats would increase attendance in three of the four models, especially

In this case we would expect the travel cost elasticity to be less than the ticket price elasticity.

11. The market price and travel cost weights are 0.75 and 0.25 , respectively. 
TABLE 4

Consumer Surplus Estimates

\begin{tabular}{|c|c|c|c|c|c|c|c|c|}
\hline \multirow[b]{3}{*}{ Consumer Surplus $(\mathrm{CS})$ per Game $(\mathrm{X})$} & \multicolumn{4}{|c|}{ Calgary Flames } & \multicolumn{4}{|c|}{ Edmonton Oilers } \\
\hline & \multicolumn{2}{|c|}{ Attend = 1} & \multicolumn{2}{|c|}{ Attend $=0$} & \multicolumn{2}{|c|}{ Attend = 1} & \multicolumn{2}{|c|}{ Attend $=0$} \\
\hline & $\mathrm{CS} / \mathrm{X}$ & $t$-stat & $\mathrm{CS} / \mathrm{X}$ & $t$-stat & $\mathbf{C S} / \mathbf{X}$ & $t$-stat & $\mathrm{CS} / \mathrm{X}$ & $t$-stat \\
\hline Status quo & 50.37 & 15.66 & 22.92 & 23.12 & 50.14 & 10.63 & 21.71 & 14.60 \\
\hline Change in CS per Game & $A \mathrm{CS} / \mathrm{X}$ & $t$-stat & $A \mathrm{CS} / \mathrm{X}$ & $t$-stat & $A \mathrm{CS} / \mathrm{X}$ & $t$-stat & $A \mathrm{CS} / \mathrm{X}$ & $t$-stat \\
\hline With current arena & 8.89 & 5.34 & & & 10.75 & 4.30 & & \\
\hline With new arena for metro residents & 11.92 & 6.14 & 44.52 & 14.84 & 0.22 & 0.13 & 15.59 & 5.84 \\
\hline With new arena for Alberta residents & 29.10 & 8.37 & 35.66 & 10.29 & 21.30 & 6.07 & 29.98 & 7.58 \\
\hline Additional place in standings & 2.95 & 6.38 & 5.52 & 2.85 & 2.14 & 5.18 & 8.37 & 8.89 \\
\hline With new arena and green design & 13.65 & 1.17 & 5.97 & 0.37 & -2.26 & -0.17 & -7.26 & -0.71 \\
\hline With new arena and casino & 11.35 & 0.75 & -1.87 & -0.10 & -1.20 & -0.08 & 29.58 & 1.95 \\
\hline With new arena and affordable housing & 14.37 & 0.85 & 5.58 & 0.33 & -8.62 & -0.62 & -1.63 & -0.13 \\
\hline With new arena and cultural complex & -31.01 & -1.87 & -13.91 & -0.74 & 17.41 & 1.18 & 19.02 & 1.29 \\
\hline
\end{tabular}

for the nonmetropolitan Alberta sample in three of the four models. According to the marginal effects, ${ }^{12}$ Flames attendees and nonattendees would go to two more games each year. Fifty-six percent of Oilers nonattendees would attend one more game each year. Those from nonmetropolitan Alberta in the Flames market who already attended games would attend an additional three games in addition to the two suggested by the NEWARENA coefficient each year. Those from the rest of Alberta in the Oilers market who already attended games would also attend an additional three games each year in a new downtown arena.

\section{Other Results}

In each model, an improvement in the standings would increase attendance. According to the marginal effects, $47 \%$ and $21 \%$ of Flames attendees and nonattendees would go to one additional game with a one-place improvement in standings, as would $26 \%$ and $30 \%$ of Oilers attendees and nonattendees. Flames attendees would go to five fewer games each year if the new arena also included a cultural complex. No other arena design features affect attendance. In terms of demographic variables, older respondents attend fewer games. For Oilers attendees, males attend two more games, married respondents attend almost three fewer games, and each two years of schooling reduces attendance by one game. Oilers nonattendees would go to one additional game if the new arena contained a casino.

12. Marginal effects are not reported in Table 3.

\section{BENEFITS}

The demand models in Table 3 provide the basis for consumer surplus estimates in Table 4. All of the consumer surplus values are obtained from the stated preference price coefficient. We use the demand slope based on the variation in stated preference prices with a new arena, which are lower than what most attendees paid for their tickets, to extrapolate the demand curve to the choke price. To the extent that this extrapolation is inaccurate, the consumer surplus results are inaccurate.

\section{A. Consumer Surplus per Game}

The status quo consumer surplus per game is $\$ 50$ for both the Flames and Oilers attendees $\left(\$ 50.37\right.$ and $\$ 50.14$ in Table $4^{13}$ ) and $\$ 23$ and \$22 for Flames and Oilers nonattendees. That attendee consumer surplus exceeds that for (revealed preference) nonattendees makes theoretical sense as the willingness and ability of nonattendees to pay for a game is lower according to the revealed preference of nonattendance.

Consumer surplus per game may be an underestimate of the total value of the game trip for all consumers. The full value of the game trip is the consumer surplus of a game trip considering both ticket prices and travel costs. The only statistically significant coefficient for travel cost is for game attendees in the Flames market. The full-price consumer surplus per game trip, $\$ 103$, is weighted by the dollar shares of the different

13. Consumer surplus numbers reported in the text are rounded. 
costs. However, interpretation of the full-price consumer surplus per game trip is complicated by the possibility of multipurpose trips. As the travel cost coefficient is statistically insignificant in the other three models we do not further discuss its effect on the value of game trips until the conclusions, except to note that consumer surplus per game estimates do not include these values.

Under the latent demand interpretation of the revealed preference dummy variable indicating that respondents would attend more games if seats were available - the consumer surplus for attendees is $\$ 9$ per game and $\$ 11$ for each additional Flames and Oilers game with the current arena and ticket prices, assuming the respondent could obtain a ticket. This result makes intuitive sense as additional games are subject to diminishing returns and should be expected to generate lower value.

The change in consumer surplus for each additional game in a new downtown arena is $\$ 12$ and $\$ 45$ for Flames attendees and nonattendees residing in Calgary, and $\$ 0$ and $\$ 16$ for Oilers attendees and nonattendees living in Edmonton. In nonmetropolitan Alberta the consumer surplus of each additional game in a new downtown arena is \$29 and \$36 for Flames attendees and nonattendees, and $\$ 21$ and $\$ 30$ for Oilers attendees and nonattendees. The quality factor can be interpreted either as an increase in perceived value of games in a new arena with additional amenities or, in the case of Edmonton, that the downtown location is preferred because of more convenience or proximity to additional downtown amenities.

The bandwagon effect is evident in that each additional place in the standings is worth $\$ 3$ and $\$ 6$ in additional consumer surplus per game to Flames attendees and nonattendees, and $\$ 2$ and $\$ 8$ to Oilers attendees and nonattendees. Adding a casino to a new downtown arena would increase consumer surplus by $\$ 30$ per game for current Oilers nonattendees. But, perhaps indicating that artistic culture and sport do not mix (Johnson et al. 2007), adding a cultural complex to a new arena in Calgary would reduce consumer surplus per game by $\$ 31$ for Flames attendees.

\section{B. Consumer Surplus per Season}

Combining the marginal effects (trip) estimates with the consumer surplus per game estimates provides estimates of the change in consumer surplus per season. Considering the status quo without the inclusion of travel costs or higher ticket prices, Flames fans who attend an average of five games enjoy consumer surplus of \$261 over the course of the season. Oilers fans who attend an average of four games enjoy consumer surplus of $\$ 193$ per season. Flames and Oilers fans who attend games would enjoy an additional $\$ 13$ and $\$ 14$ per season, if seats were always available.

With a new arena, Flames attendees and nonattendees and Oilers nonattendees in the metropolitan area would enjoy an additional $\$ 23, \$ 75$, and $\$ 9$ in consumer surplus over the course of the season. Similarly, with a new arena, Flames attendees and nonattendees, and Oilers attendees and nonattendees from nonmetropolitan Alberta would enjoy an additional $\$ 136, \$ 48, \$ 56$, and $\$ 32$ in consumer surplus over the course of the season. As the impact on consumer surplus of a rise in the standings affects all games attended, not only the increase in games, the seasonal effect on consumer surplus is the product of the change in consumer surplus per trip and the sum of baseline trips and the marginal effect of a change in the standings. Flames attendees and nonattendees would enjoy \$14 and \$27 in additional consumer surplus during the season, while Oilers attendees and nonattendees would get an additional \$11 and $\$ 41$ for a one-unit rise in the standings. Assuming the value of games attended with a new arena is also affected, the cost of a cultural complex to Flames attendees is $\$ 53$ in lost consumer surplus over the course of the season. The benefit of a casino to current Oilers nonattendees is $\$ 46$ in additional consumer surplus over the course of the season.

\section{Policy Implications}

Our results can be used to inform policy makers. Most major league sports stadiums and arenas in North America have been built with extensive public subsidies. Long (2005) calculates an average present value of public subsidies, in 2001 dollars, of $\$ 175$ million for each of the 99 major league hockey, basketball, football, and baseball facilities in use in 2001 in North America. An extensive literature measuring the economic impact of stadiums and arenas on jobs, taxes, and incomes concludes that the economic impacts are much too small to warrant such subsidies on efficiency grounds. See, for example, Baade (1996), Noll and Zimbalist (1997), or 
Coates and Humphreys (1999). See Coates (2007) for an overview of the literature. Others have measured the benefits from public goods, such as civic pride, produced by sports teams. They reach the same conclusion as the analyses of the economic impacts - such large subsidies cannot be justified on efficiency grounds. See Johnson, Groothuis, and Whitehead (2001) and Johnson, Mondello, and Whitehead (2007) for examples, or Johnson (2008) for an overview of the literature.

Studies of economic impacts or public goods, however, do not address the consumption benefits as does the current paper. Could consumption benefits enjoyed by game attendees make public subsidies efficient? There are a number of alternative benefit-cost analysis scenarios and we consider only one. We estimate the benefits of a new arena by the sum of consumer surplus of additional seats and the additional consumer surplus of improved seating of the existing number of seats. We assume the new arena reaches the maximum NHL capacity of 21,273 seats and the additional seats are filled with (revealed preference) nonattendees. The per game consumer surplus for additional seats in a new arena is $\$ 45$ and $\$ 16$ for those metropolitan residents in the Calgary and Edmonton markets who do not currently attend games. Forty-one home sellout games would generate annual consumer surplus of \$3.6 million and \$2.8 million in Calgary and Edmonton for the additional seating capacity. The Calgary Flames would generate additional consumption benefits with a new arena. Current metropolitan attendees in the Calgary Flames market would enjoy an additional $\$ 12$ in consumer surplus per game in a new arena. At current arena capacity over 41 home games, the annual benefit of additional quality for the existing number of seats is $\$ 9.5$ million. The total annual benefit of a new arena in Calgary is $\$ 13$ million. The annual benefit of additional arena quality in the Edmonton Oilers market is zero, so the total annual benefit of a new arena is $\$ 2.8$ million.

We consider two alternative discount rates: $2 \%$ and $7 \%$. With a $2 \%$ discount rate and consumption benefits accruing for 30 years, the present value of consumer surplus is \$292 million in Calgary and $\$ 63$ million in Edmonton. With a $7 \%$ discount rate, the present value of consumer surplus is $\$ 162$ million in Calgary and $\$ 35$ million in Edmonton. A new NHL arena costs between $\$ 275$ million and $\$ 450$ million. Therefore, the consumption benefits of new seating for the Edmonton Oilers do not appear to justify a new downtown arena when future benefits are discounted at $2 \%$ and $7 \%$. Considering the Calgary Flames, the consumption benefits only justify a new arena in a best case scenario: at the lower end of the range of arena costs and when future consumption benefits are discounted at $2 \%$.

While a benefit-cost analysis is beyond the scope of this paper, a number of issues should be considered. A sensitivity analysis of the benefit estimates should consider the full consumer surplus of Flames game trips based on ticket prices and travel costs. As the status quo consumer surplus is about twice as high when considering travel costs, the economic benefits of a new arena would be much higher and could justify new arena construction.

These figures suggest that in some cases, consumption benefits may help justify on efficiency grounds the large public subsidies typically offered for new stadiums and arenas. This is not to say that subsidies are good public policy. There may be other projects that would produce greater benefits for the amount spent. Teams may be able to extract much of the consumer surplus through personal seat licenses or through price discrimination, making subsidies unnecessary. Nevertheless, this paper, the first to estimate consumer surplus from data on individual fan preferences, finds that large gains in consumer surplus may render some stadium subsidies much less inefficient than suggested by studies of the economic impacts and public goods alone.

\section{CONCLUSIONS}

This paper is the first to estimate game trip demand functions for individual sports fans using microdata. Because capacity constraints are often binding in the NHL, estimation of individual hockey demand functions using revealed preference data alone would be difficult, even if individual-level microdata were available. The results show that hockey fans who already attend games would buy more tickets each year if seats were available at lower prices. The results also show that fans are sensitive to team quality, and that each rung a team climbs in its divisional standings will increase game trip demand. We include travel costs as an additional variable to explain demand behavior and find some evidence that it is a significant determinant of game attendance. The full-price consumer surplus per 
game trip is twice as great as the consumer surplus per game.

Binding capacity constraints have a large impact on the number of games attended by metropolitan fans of the Calgary Flames, imposing a large deadweight loss. Capacity constraints also have a large effect on nonmetropolitan Alberta residents in both markets. These results suggest that the benefits of new arenas in Calgary and Edmonton would accrue to a large extent to nonmetropolitan residents. That the capacity constraints could impose such large welfare costs may seem surprising, but other evidence is consistent with this conclusion. For instance, the average ticket prices in Calgary and Edmonton are among the highest in the NHL, according to Team Marketing Report, a firm that compiles ticket price data for professional sports teams. The high ticket prices and sold out seasons, along with the fact that Calgary and Edmonton are among the smallest metropoli$\tan$ areas in the NHL, are evidence of a high per capita demand for hockey tickets, consistent with the survey responses and estimated demand functions in this paper.

Stadium and arena complexes built or proposed in the past decade have increasingly included features and amenities far beyond the actual sports building. Petco Field, a baseball stadium in San Diego, and Nationwide Arena, a hockey arena in Columbus, Ohio, are the anchors of development districts including housing, entertainment, and other features. Proponents of stadiums and arenas as tools for urban revitalization often argue that sports venues alone cannot succeed in transforming decaying urban districts. Other types of development, together with a stadium or arena, they say, can bring round-the-clock activity and life to a downtown or other depressed neighborhood (Rosentraub 2008).

We find that features such as housing, arts and cultural space, and casinos in arena development projects would have little effect on the demand for hockey tickets in Calgary and Edmonton, with two exceptions. Demand for hockey by Calgarians who already attend games would fall if a new arena complex included arts and cultural space, while demand for Oilers tickets by non-Edmontonians would rise substantially if a casino were built alongside a new arena. That nonsports features mostly have no effect on demand for hockey, and may even decrease the demand for hockey, suggests that increased consumer surplus of hockey fans cannot be considered a benefit of diversity in development projects. However, these additional features may attract nonhockey fans to the development complex.

The results of the status quo annual consumer surplus estimation in this paper, based on individual demand functions estimated from both revealed and stated preference data, are broadly consistent with the estimates of annual consumer surplus from MLB developed by Irani (1997). Using the full consumer surplus of a new arena for the Calgary market would suggest that the efficient outcome is to build the arena. However, as the benefits would accrue to the fans attending games rather than to the public at large, and because the Flames could finance much of the cost by extracting additional consumer surplus, it would be difficult to use the increased consumer surplus to justify a public subsidy.

Future research should investigate more detailed hypothetical scenarios to determine the sensitivity of our results to survey design. New stadiums and arenas incorporate many advances in construction technology and architectural design that result in higher demand for tickets. Better sightlines, more restrooms, restaurants, and concession stands made easily accessible by wide aisles and concourses make for more comfortable environments for spectators. Such improvements mean that, at least in the honeymoon period, fans are willing to buy more tickets at higher prices. The hypothetical scenarios presented in the surveys in Alberta did not mention such amenities. Perhaps respondents assumed such amenities, common in new arenas, would be included. But to the extent they did not, the potential gains to consumer surplus from a new arena might be different than the gains estimated in this paper.

Further, our analysis is limited in a number of ways. A potentially important independent variable for game attendees is the actual ticket price paid. Our survey design put little emphasis on collection of this variable. Future research should consider the relationship between ticket prices and individual game attendance. We also are cavalier about capacity constraints in the hypothetical new arenas. If actual demand for seats in a new arena exceeds capacity then ticket prices will rise and consumer surplus will be transferred to producers or ticket dealers and our consumer surplus estimates will be biased upwards.

Two econometric issues related to revealed and stated preference data are not addressed. 
First, revealed preference data collection likely suffers from recall bias and digit bias which results in measurement error. This may result in inflated standard errors for our coefficients. Second, we employ the random effects Poisson model which is the most stable of the count data models applied to panel data. However, as our dependent variable contains a large number of zeros, zero-inflated Poisson models may be preferred. Future research should pursue a comparison of alternative count data models in the context of combined revealed and stated preference data.

Previous nonmarket valuation methods, such as the CVM, applied to sports public goods have been used in isolation from others. Future research should use multi-methods and consider the convergent validity of consumer surplus estimates. For example, a comparison study between the hedonic pricing method, CVM, and travel cost method could be designed to estimate the benefits of sports teams to a city. If the consumer surplus estimates converge, or diverge for theoretical or methodological reasons, then confidence in the individual estimates is enhanced.

\section{APPENDIX: SURVEY QUESTIONS}

This appendix provides the telephone survey questions used to elicit revealed and stated preference data for the Calgary Flames games. Similar questions were used for the Edmonton Oilers games. The full survey can be found at http://econ.appstate.edu/AGRI or upon request from the authors.

The next few questions are about your attendance at Calgary Flames games.

C1. How many Calgary Flames games did you attend during the 2006-07 season? games-if zero, skip to C3.

$\mathrm{C} 2$. About how much do you usually pay for your Flames tickets? dollars

C3. Suppose the Flames are expected to finish first in their division and challenge for the Stanley Cup this season. About how many Flames games would you plan to attend in Calgary this season?

$$
\text { games-if zero, go to C6 }
$$

C4. Now suppose that the Flames are expected to finish last in their division. About how many Flames games would you plan to attend in Calgary this season? games

C5. Now suppose that the Flames are expected to finish third in their division and make the playoffs this season. About how many Flames games would you plan to attend in Calgary this season? games

C6. Suppose that the Flames build a new professional hockey arena $[+$ casino, affordable housing, cultural complex] in downtown Calgary. The new arena will have additional upper level seating with unobstructed views and luxury suites. For these questions, please assume that your personal situation stays the same. For example, you have the same job, income and family situation. Also assume that the Flames are expected to finish third in their division and make the playoffs. OK?

C7. If other ticket prices don't change at the new arena and there are plenty of additional upper level seats with unobstructed views available at a price of $\$ 20$ per game, how many Flames games would you plan to attend in the new downtown Calgary arena during the season?

$$
\text { games }
$$

C8. If the tickets for the additional upper level seats with unobstructed views are available at a price of $\$ 10$ per game, how many Flames games would you plan to attend in the new downtown Calgary arena during the season? games

C9. If the tickets for the additional upper level seats with unobstructed views are available at a price of $\$ 30$ per game, how many Flames games would you plan to attend in the new downtown Calgary arena during the season? games

\section{REFERENCES}

Alexander, D. L., W. Kern, and J. Neill. "Valuing the Consumption Benefits from Professional Sports Franchises." Journal of Urban Economics, 48, 2000, 321-37.

Baade, R. A. "Professional Sports as Catalysts for Metropolitan Economic Development." Journal of Urban Affairs, 18(1), 1996, 1-17.

Bockstael, N. E., and I. E. Strand. "The Effect of Common Sources of Regression Error on Benefit Estimates." Land Economics, 63, 1987, 11-20.

Borland, J., and R. Macdonald. "Demand for Sport." Oxford Review of Economic Policy, 19(4), 2003, 478-502.

Bruggink, T. H., and J. W. Eaton. "Rebuilding Attendance in Major League Baseball: The Demand for Individual Games," in Baseball Economics: Current Research, edited by J. Fizel, E. Gustafson, and L. Hadley. Westport, CT: Praeger, 1996, 9-31.

Burdekin, R. C. K., and T. L. Idson. "Customer Preferences, Attendance and the Racial Structure of Professional Basketball Teams." Applied Economics, 23, 1991, 179-86.

Butler, M. R. "Interleague Play and Baseball Attendance." Journal of Sports Economics, 3(4), 2002, 320-34.

Carlino, G., and N. E. Coulson. "Compensating Differentials and the Social Benefits of the NFL." Journal of Urban Economics, 56(1), 2004, 25-50.

- "Compensating Differentials and the Social Benefits of the NFL: Reply." Journal of Urban Economics, 60(1), 2006, 132-8.

Clarke, P. M. "Testing the Convergent Validity of the Contingent Valuation and Travel Cost Methods in Valuing the Benefits of Health Care." Health Economics, 11, 2002, 117-27.

Coates, D. "Stadiums and Arenas: Economic Development or Economic Redistribution?" Contemporary Economic Policy, 25(4), 2007, 565-77.

Coates, D., and T. Harrison. "Baseball Strikes and the Demand for Attendance." Journal of Sports Economics, 6(3), 2005, 282-302.

Coates, D., and B. R. Humphreys. "The Growth Effects of Sports Franchises, Stadia, and Arenas." Journal of Policy Analysis and Management, 18(4), 1999, 601-24.

"Proximity Benefits and Voting on Stadium and Arena Subsidies." Journal of Urban Economics, 59(2), 2006, 285-99. 
Coates, D., B. R. Humphreys, and A. Zimbalist. "Compensating Differentials and the Social Benefits of the NFL: A Comment." Journal of Urban Economics, 60(1), 2006, 124-31.

Czarnitzki, D., and G. Stadtmann. "The Uncertainty of Outcome Versus Reputation: Empirical Evidence for the First German Football Division." Empirical Economics, 27(1), 2002, 101-12.

Dehring C. A., C. A. Depken II, and M. R. Ward. "A Direct Test of the Homevoter Hypothesis." Journal of Urban Economics, 64(1), 2008, 155-70.

Donihue, M. R., D. W. Findlay, and P. W. Newberry. "An Analysis of Attendance at Major League Baseball Spring Training Games." Journal of Sports Economics, 8(1), 2007, 39-61.

Fenn, A. J., and J. R. Crooker. "Estimating Local Welfare Generated by an NFL Team under Credible Threat of Relocation.” Southern Economic Journal, 76(1), 2009, 198-223.

Garcia, J., and P. Rodriguez. "The Determinants of Football Match Attendance Revisited: Empirical Evidence from the Spanish Football League." Journal of Sports Economics, 3(1), 2002, 18-38.

Grijalva, T. C., R. P. Berrens, A. K. Bohara, and W. D. Shaw. "Testing the Validity of Contingent Behavior Responses." American Journal of Agricultural Economics, 84(2), 2002, 401-14.

Haab, T. C., and K. E. McConnell. Valuing Environmental and Natural Resources: The Econometrics of Nonmarket Valuation. Northampton, MA: Edward Elgar, 2002

Hausman, J., B. H. Hall, and Z. Griliches. "Econometric Models for Count Data with an Application to Patents - R\&D Relationship." Econometrica, 52, 1984, 909-38

Hynes, S., N. Hanley, and C. O’Donoghue. "Alternative Treatments of the Cost of Time in Recreational Demand Models: An Application to Whitewater Kayaking in Ireland." Journal of Environmental Management, 90(2), 2009, 1014-21.

Irani, D. "Public Subsidies to Stadiums: Do the Costs Outweigh the Benefits?" Public Finance Review, 25, 1997, 238-53.

Johnson, B. K. "The Valuation of Non-Market Benefits in Sport," in The Business of Sports, Vol. 2, Chapter 9, edited by B. R. Humphreys and D. R. Howard. Westport, CT: Praeger, 2008, 207-233.

Johnson, B. K., and J. C. Whitehead. "Value of Public Goods from Sports Stadiums: The CVM Approach." Contemporary Economic Policy, 18(1), 2000, 48-58.

Johnson, B. K., P. A. Groothuis, and J. C. Whitehead. "The Value of Public Goods Generated by a Major League Team: The CVM Approach." Journal of Sports Economics, 2(1), 2001, 6-21.

Johnson, B. K., M. J. Mondello, and J. C. Whitehead. "The Value of Public Goods Generated by a National Football League Team.” Journal of Sport Management, 21(1), 2007, 123-36.

Johnson, B. K., J. C. Whitehead, D. S. Mason, and G. J. Walker. "Competition for Government Funding in Arts and Sports: The Lace Underwear Set vs. the Jockstrap Crowd." Paper presented at the International Atlantic Economic Society Meetings, Savannah, GA, 2007.

Kahane, L., and S. Shmanske. "Team Roster Turnover and Attendance in Major League Baseball." Applied Economics, 29, 1997, 425-31

Kom, J. "Dome Dreams: As a Brash Kid, Our City's Arena Welcomed the 1988 Olympics, but the Hockey Hotshot Is Now an Aging Player in the Sports World." Calgary Herald, 2008, April 6, B1.
Landry, C. E., and H. Liu. "Econometric Models for Joint Estimation of RP-SP Site Frequency Recreation Demand Models," in Preference Data for Environmental Valuation: Combining Revealed and Stated Approaches, edited by J. C. Whitehead, T. C. Haab, and J.-C. Huang. London: Routledge, 2011.

Leadley, J. C., and Z. X. Zygmont. "When Is the Honeymoon Over? National Hockey League Attendance." Canadian Public Policy, 32(2), 2006, 213-32.

Long, J. G. "Full Count: The Real Cost of Public Funding for Major League Sports Facilities." Journal of Sports Economics, 6(2), 2005, 119-43.

Mah, B. "Plan for an Aging Rexall." Edmonton Journal, 2007, February 22, A3.

Mason, D. S. "The Stadium Game in an Uncertain Environment: A Preliminary Look at Arena Discourse in Edmonton, Canada," in Optimal Strategies in Sports Economics and Management, edited by S. Butenko, J. Gil-Lafuente, and P. M. Pardalos. London: Springer, 2010, 97-124.

Noll, R., and A. Zimbalist, eds. Sports, Jobs, and Taxes: The Economic Impact of Sports Teams and Stadiums. Washington, DC: Brookings Institution, 1997.

Paul, R. "Variations in NHL Attendance: The Impact of Violence, Scoring, and Regional Rivalries." American Journal of Economics and Sociology, 62(2), 2003, 345-64.

Phaneuf, D. J., and V. K. Smith. "Recreation Demand Models," in Handbook of Environmental Economics: Volume 2, Valuing Environmental Changes, Chapter 15, edited by K.-G. Mäler and J. R. Vincent. Elsevier North-Holland, 2005.

Price, D., and K. Sen. "The Demand for Game-Day Attendance in College Football: An Analysis of the 1997 Division I-A Season." Managerial and Decision Economics, 24, 2003, 35-46.

Rosentraub, M. S. "Sports Facilities and Urban Redevelopment: Private and Public Benefits and a Prescription for a Healthier Future," in The Business of Sports, Volume 3: Bridging Research and Practice, Chapter 3, edited by B. R. Humphreys and D. R. Howard. Westport, CT: Praeger, 2008

Sports Business Journal. "By the Numbers 2003," 30 December 2002, 5(36), 91, 111.

Tarrant, M. A., and M. J. Manfredo. "Digit Preference, Recall Bias, and Nonresponse Bias in Self Reports of Angling Participation." Leisure Science, 15(3), 1993, 231-38.

Welki, A. M., and T. J. Zlatoper. "US Professional Football: The Demand for Game-Day Attendance in 1991." Managerial and Decision Economics, 15, 1994, 489-95.

. "US Professional Football Game-Day Attendance." Atlantic Economic Journal, 27(3), 1999, 285-98.

Whitehead, J. C. "Environmental Risk and Averting Behavior: Predictive Validity of Revealed and Stated Preference Data." Environmental and Resource Economics, 32(2), 2005, 301-16.

Whitehead, J. C., S. K. Pattanayak, G. L. Van Houtven, and B. R. Gelso. "Combining Revealed and Stated Preference Data to Estimate the Nonmarket Value of Ecological Services: An Assessment of the State of the Science." Journal of Economic Surveys, 22(5), 2008, 872-908.

Zygmont, Z. X., and J. C. Leadley. "When Is the Honeymoon Over? Major League Baseball Attendance 19702000." Journal of Sport Management, 19(3), 2005, 278-99. 